\title{
El proceso de valoración de los centros educativos por parte de las familias de clase media. El papel del orden expresivo en la búsqueda de la «distinción»
}

\author{
Antonio Olmedo Reinoso \\ Luis Eduardo Santa Cruz Grau \\ Facultad de Ciencias de la Educación. Campus de Cartuja. Universidad de Granada \\ olmedo@ugr.es \\ esantacruz@ugr.es
}

\section{Resumen}

El presente artículo analiza la valoración que realizan las familias de clase media sobre el orden expresivo de distintos centros educativos. La composición social del alumnado, el proyecto educativo, la titularidad y el ambiente general son aspectos valorados por los padres durante el proceso de escolarización de sus hijos. Buscarán centros con «prestigio social», sean éstos públicos o privados, donde acudan otras familias con similares características socioculturales, con las que compartan valores y ambiciones. Concluimos que el proceso de elección de centro forma parte de aquellas dinámicas de cierre social destinadas a posicionar a los hijos en una situación privilegiada y ventajosa frente a otros.

Palabras clave: elección de centro; orden expresivo; clase social; clases medias; cierre social.

Abstract. The evaluation process of schools by middle-class families. The role of the expressive order in the search for distinction

This article analyses the evaluation made by middle-class families regarding the expressive order of different schools. The social composition of the pupils, the educational project, their public or private character and the general atmosphere are highly valued aspects by those parents during the schooling process of their children. They look for schools with «social prestige», either public or private, where other families with similar socio-cultural characteristics, values and ambitions are also sending their children. We conclude that the school choice process is part of wider social closure dynamics destined to situate their children in a more privileged and advantageous position.

Key words: school choice; expressive order; social class; middle classes; social closure. 


\section{Sumario}

Más allá de la escuela pública o privada.

La importancia del "prestigio social»

La escuela privada como garantía de selección

La escuela pública: entre la «solidaridad» y la «distinción»
El proyecto educativo: un punto de confluencia entre escuela y familia

El ambiente general de un centro: la búszqueda del entorno propicio A modo de síntesis

Referencias bibliográficas

En el presente artículo, analizamos el proceso de valoración de los centros desde la perspectiva de un grupo de familias de clase media en el marco de un mercado educativo local. En concreto, nos interesa conocer cómo la opinión que se tiene de los centros gira en torno a variables que, a diferencia de lo que podría esperarse en un entorno en el que la elección se va planteando de forma cada vez más libre (Olmedo, 2008a), no responde tanto a criterios académicos como a otros relacionados con la clase social de las familias, el entorno social de los centros, los aspectos ideológicos, etc. De esta forma, la elección de centro también está marcada por aspectos relacionados con la localización, los recursos materiales de que se dispone y las circunstancias sociales que rodean a la familia (Bowe et al., 1994). De ahí que nuestro interés radique no sólo en identificar los distintos criterios que llevaron a los padres de clase media a elegir un centro frente a otro, sino también en analizar las ideas y las razones que les llevaron a considerar tales criterios, el perfil de centro que iban buscando y las estrategias que ponen en práctica, sabiendo de antemano que "conseguir» el "centro perfecto» es tarea imposible.

$\mathrm{Al}$ igual que Power y sus colegas (2003), consideramos importante analizar este proceso partiendo del modelo propuesto por Bernstein (1988) para indagar sobre las aproximaciones a la "cultura escolar» desarrolladas por los padres. Bernstein divide dicha cultura escolar en dos «órdenes» de elementos: el «instrumental» y el «expresivo». En una publicación anterior (Olmedo y Santa Cruz, 2008), nos centramos en el primero de ellos. Allí desarrollamos aspectos relacionados con la valoración, por parte de las familias, de elementos como el nivel académico de los centros, el seguimiento y el acompañamiento de los alumnos, la metodología y los métodos pedagógicos y la percepción sobre la calidad y la disponibilidad del profesorado, entre otros aspectos. En el presente artículo, desarrollaremos el orden expresivo, el cual hace referencia al "complejo de conductas y actividades en la escuela que se refiere a la conducta, el carácter y los modales» (Bernstein, 1988: 38). Se trata de un "orden moral que se aplica a cada alumno y a cada profesor», el cual «tiende a compactar a toda la escuela en tanto que colectividad moral» (ídem). Por tanto, nuestro objetivo coincide con el señalado por el propio Bernstein al referirse a la utilidad de dicha clasificación, mediante la cual es posible encontrar una asociación entre la clase social y la relación de la familia con la escuela. Ball (2003a), a su vez, también reconoce este aspecto y lo relaciona con dinámicas más generales de 
reproducción social. El presente artículo es el resultado de un estudio cualitativo sobre las motivaciones, las estrategias y el discurso de las familias de clase media respecto al proceso de elección de centro educativo para sus hijos. El interés por estudiar esta clase social en concreto se fundamenta en la detección de estrategias de agregación mediante la elección por parte de estas familias en investigaciones previas, tanto en el contexto internacional (Ball, 2003a; Van Zanten, 2003), como nacional (Olmedo, 2008b; Rambla, 2003).

En esta ocasión, se presenta el análisis de una serie de entrevistas realizadas a un grupo de 24 familias (16 madres y 14 padres) de clase media. Para la selección de la muestra, se establecieron dos características principales que debían cumplir los sujetos. En primer lugar, relacionado con la posición de clase, se estableció un filtro sobre el nivel de estudios, de modo que al menos uno de los progenitores de cada familia hubiera completado estudios universitarios, ya fuera a nivel de diplomatura o de licenciatura. En segundo término, sobre la posición ocupacional de los padres, de manera que uno de ellos ejerciera una ocupación dentro de los grupos definidos como profesionales, administrativos o directivos. Dentro de estas familias, 9 envían a sus hijos a centros públicos, 9 lo hacen a centros privados concertados (de los cuales tan sólo 1 mantiene el concierto en el nivel de bachillerato) y 6 a centros priva$\operatorname{dos}^{1}$. Como tercer criterio, se estableció como condición que sus hijos estuvieran cursando el nivel de bachillerato. Por último, una vez transcritas, el análisis de las entrevistas se realizó siguiendo los principios propuestos desde la perspectiva de la Teoría Fundada (Grounded Theory) desarrollada por Strauss y Corbin (1998).

\section{Más allá de la escuela pública o privada. La importancia del «prestigio social»}

En un mercado educativo, especialmente a nivel local, las escuelas ostentan un cierto prestigio social que han ido forjando a lo largo del tiempo. Ese prestigio se relaciona, en diferente grado, con el número de aprobados en pruebas selectivas, con el hecho de formar parte de una determinada red de centros o con la población que tradicionalmente atiende. El modo en que se jerarquizan y se combinan estas variables depende de las características específicas de los distintos mercados educativos locales y del tipo de familias en el que centremos nuestra atención. De esta manera, la elección de centro tendrá siempre un componente local que es

1. Debemos tener presente que la mayoría de los centros privados concertados pierden la financiación pública para el nivel de bachillerato. A partir de esta etapa, su carácter y regulación es similar al de los centros estrictamente privados. El hecho que determinados centros mantengan el concierto en dicho nivel, y con ello la financiación pública, se debe a la consideración de posibles fines sociales en el contexto en el que se encuentren o a razones relacionadas con el devenir histórico de los propios mercados educativos locales, sin necesidad de responder a ningún otro motivo relacionado con una determinada utilidad social (como sería el caso del centro al que nos referimos en nuestro estudio). 
importante determinar y que podrá estar relacionado, entre otros factores, con la historia y el peso específico de la educación privada y concertada, con las características socioeconómicas de la población, con el diseño de las zonas de escolarización o con el grado de segregación social existente en la ciudad.

Un primer elemento que está presente en el discurso de estas familias es que el prestigio social no es un atributo exclusivo de una red educativa en concreto, sino que tanto centros privados como públicos participan en este juego. Aunque se trata de un rasgo extensivo prácticamente a la totalidad de los privados, también un segmento de los centros públicos goza de estima social y, por ende, cuenta con una elevada demanda por parte de los padres. Para el caso español, Bernal sostiene que la propia red pública se compone de tres micromercados, cuyo principal rasgo de diferenciación lo constituye el grupo social de procedencia del alumnado. El primero de estos micromercados - $\mathrm{O}$ «espacios socioculturales», como también los llama el autor- estaría constituido por centros públicos de elevado prestigio social, seculares en su proyecto educativo, sin problemas sociales de importancia y donde acuden mayoritariamente alumnos de familias de clase media. Al compararse con la red privada, estos centros públicos poseen más similitudes que diferencias. (Bernal, 2005: 786). Esto último pone en evidencia el hecho que la diferenciación de los centros sólo a partir de su titularidad resulta insuficiente para explicar las complejas dinámicas de elección desarrolladas en España (Pérez-Díaz et al., 2001; Villarroya y Escardíbul, 2008). Por esto mismo es necesario considerar, junto a la tradicional distinción entre enseñanza pública y enseñanza privada, las representaciones existentes entre los padres sobre la composición social de los centros, el modo de organización de los mismos, la selección de su alumnado o la zona donde se ubican (Alegre et al., 2008; Fernández Esquinas, 2004; Mancebón y Pérez Ximénez de Embún, 2007; Valiente, 2008).

En el caso específico de Granada, algunos centros de titularidad pública funcionan de modo semejante y reciben a un alumnado similar que aquéllos de carácter privado o concertado, además, gozan entre los padres de análogo prestigio. Así, Elsa y Consuelo, al elegir centro para sus hijos en las etapas de secundaria y bachillerato, aún habiendo optado por la educación pública, son conscientes de esta situación. Ellas no buscan cualquier centro, sino que escogen aquél que posea "categoría social» $\mathrm{y}$ " prestigio reconocido»:

Me interesaba un instituto que tuviera cierto renombre, que se supiera que tenía una categoría social y que, además, los resultados, estadísticamente hablando, eran pocos suspensos frente a muchos aprobados en junio, a la hora de la Selectividad. (Elsa)

De igual manera ocurre dentro de la red privada, donde también encontramos frecuentes referencias al prestigio de distintos centros:

Ya no sólo el nivel académico que podía tener el colegio [...]. Y, entonces, bueno, aunque aquello era de nueva creación pero tenía un poco el prestigio 
de la red de centros. Y, entonces, pues, decidimos, pues, eso, el que fueran los críos aquí, y fue una decisión bastante acertada. (Julio)

[...] y es un colegio más... Bueno, digamos, dentro de los... subvencionados o... concertados... Pues, un colegio que tiene... una categoría... media. Pero lo que no lo voy a llevar, a lo mejor, es al que hay ahí en Almanjáyar, eso está claro... (Paula)

Como mencionábamos, el prestigio de los centros es acumulado por los mismos con el paso del tiempo, con lo cual se introduce la necesidad de considerar la historia propia del mercado educativo local, es decir, de analizar cómo se ha ido configurando y cuál es la trayectoria de los distintos centros que lo componen. En ese sentido, la propia experiencia escolar de los padres es fundamental para entender las imágenes que ellos tienen actualmente sobre el mercado educativo local. Esto se puede expresar tanto en el deseo que los hijos realicen la misma trayectoria educativa que los padres o, como en otros casos, en oposición frontal a ésta. Julián expresa la necesidad de dar a sus hijos lo que él, debido a sus propias circunstancias personales, no pudo tener y siempre «admiró»:

[...] yo no lo conocía, no tenía ni idea de cómo era el centro, por lo que te he dicho antes, porque mis padres no pudieron ponerme nunca en un centro privado. Yo siempre los he admirado. Los chavales que jugábamos al fútbol: «Son de los Salesianos, son de los Maristas...». Yo siempre los veía con un poquito de envidia, ¿no? Siempre iban con sus uniformes, con sus polos, con sus tal... Y dices: «Fíjate tú, estos chavales...». Y, bueno, tuve la suerte de que mi chaval entró en un colegio de ese tipo. (Julián)

La población de un centro determinado, «la relación social» que ofrece tanto a padres como a hijos, influye de forma directa en la idea de "prestigio social», lo cual constituye una variable de suma relevancia en el momento de escoger un centro. Como señala Ball, encontramos que «no son tan sólo la escuela y su profesorado objetos de escrutinio [...] lo que se está realmente comprando es quién va al mismo» (Ball, 2003a: 59-60). Debido a esto, elegir un centro para los hijos implica dedicar una atención especial a conocer las características específicas del alumnado que asiste a los distintos centros. La mayor parte de los padres entrevistados tratan de encontrar en los centros familias con ambiciones y planteamientos similares, personas con un nivel social y cultural semejante al suyo:

[...] porque donde estamos, aquí en Ciencias, la mayoría de los profesores llevan allí a sus niños, porque es un instituto que tiene muy buena fama. Todo tenía... Todo estaba a favor. (Paula)

Esos son los motivos por los que yo personalmente [prefiero] ese tipo de centros. Principalmente, la relación social que encontramos alrededor. Allí no hay problemas si hay que pagar una cuota especial... (Julián) 
Los padres señalan que no todos los centros cumplen adecuadamente el criterio antes mencionado y, por ende, ellos manifiestan estar dispuestos a utilizar los distintos tipos de capital con que cuentan para encontrar aquél que satisfaga sus expectativas. El repertorio de mecanismos y recursos del cual pueden hacer uso estas familias supera con creces a lo que se puede observar en los padres de clase obrera (Gewirtz et al., 1995). Esta situación los ubica en una posición de privilegio que no desconocen y que se encuentran dispuestos a aprovechar en el momento de escoger un centro para sus hijos.

El deseo de encontrar un centro con prestigio social suele estar inscrito en un complejo discurso que reivindica y legitima la necesidad de consolidar los rasgos de diferenciación social respecto de otros colectivos. Esto favorece la aparición de una doble situación de cierre social (Ball, 2003a). Por un lado, existe un cierto juicio atributivo de la clase social a la que se pertenece, lo que se expresa a través de la identificación con aquéllos «como nosotros». Por otro, y derivado de lo anterior, se evidencia una clara conciencia respecto a la estructura social existente, lo que lleva a muchos de ellos a desarrollar distintas estrategias y mecanismos para diferenciarse de aquéllos que no son «como nosotros» (Bourdieu, 1998). Este posicionamiento en la jerarquía social se produce tanto "hacia abajo», intentando desmarcarse de otros niños y familias de clase obrera, como "hacia arriba", evitando que la identificación se realice con personas de clase alta, los cuales, a su vez, presentan otros valores y estilos de vida.

R: Y luego quiero que estén con gente como ellas, normal. [...] yo quiero que aprendan a tratar a todo el mundo, pero yo quiero que estén con gente como ellas, que se encuentren los mismos problemas que ellas tienen. Eso no significa que yo no las deje tratar, tener amigos o hacer lo que sea con todo tipo de gente, pero no ocho horas al día en el colegio...

E: ¿A qué te refieres con eso?

R: Pues, porque, por ejemplo, yo nunca tendría a mis hijas en un colegio público de Almanjáyar. Pues, porque..., porque no se van a encontrar ubicadas, como dicen los sudamericanos, porque a lo mejor sus problemas no son los mismos que puedan tener otros chiquillos. Estas niñas han tenido la suerte de nacer en una familia donde a lo mejor les pueden dar cinco y el otro chiquillo ha tenido la mala suerte de nacer en una familia donde le pueden dar uno. Pues, resulta que mi hija no tiene por qué sentirse mal porque ella, que no lo ha elegido sino que ha nacido, [...] Yo tampoco tengo a mis hijas en un colegio del príncipe Felipe, ¿sabes?, porque le pasa lo mismo, el príncipe Felipe tiene 10 y la mía tiene 5, con lo cual tampoco me parece que tiene que estar con niños que su máxima ilusión en la vida sea montar a caballo e irse a esquiar a Saint Moritz, porque la mía no puede hacerlo... (Laura)

De esta forma, chicos y chicas de clase media deben aprender a interiorizar las disposiciones asociadas a su procedencia de clase, donde, parafraseando a Laura, «el destino» les ha situado. 


\section{La escuela privada como garantía de selección}

Los colegios privados se presentan como una garantía que se asistirá a un centro con prestigio social. De esta forma, coincidimos con los resultados de la investigación de Ball, donde se concluye que «el sector privado es una posibilidad eternamente presente, una tentación, una ruta de escape, un recurso obvio para muchos de estos padres; esto es, para aquéllos que pueden permitirse el pago de las cuotas» (2003a: 55). En el caso de aquéllos que escogieron centros privados, dos son los argumentos más utilizados para justificar dicha elección. En primer lugar, la posibilidad de elegir o controlar el tipo de relaciones que entablará su hijo. El hecho de que sus hijos puedan encontrar "malos» compañeros de clase y, por tanto, recibir «malas» influencias, preocupa mucho a estas familias; es algo que "da miedo», en palabras de Puri. Dentro de un discurso donde se destaca el esfuerzo invertido en lograr un entorno estable y facilitador para sus hijos, la influencia del grupo de pares constituye un elemento que perturba y preocupa a los padres, pues podría tener consecuencias negativas para el futuro de sus hijos.

[...] a lo mejor si hubiera vivido en el centro... Si hubiera quedado en el Virgen de Gracia, yo no tengo ningún problema... Lo que me obligó a cambiarlo fue la situación... nuestra. Aquí no hay colegios... Bueno, ahí hay un colegio, pero yo no quiero llevarlo ahí... porque yo sé lo que hay en toda la calle, y yo no quiero que esté... y hay de todo... y no he querido, y como tengo nada más que uno... (Paula)

[...] porque no sé con quien se va a juntar. Entonces, el miedo a que tenga otras junteras y me lo lleven por otro sitio. Como ahí yo lo tengo más o menos controlado, pues, prefiero que siga o en ese colegio o yo busco uno que me dé confianza. Que no me importa gastarme el dinero con tal de que mi hijo saque una buena educación. (Puri)

La preocupación por el cuidado de los hijos se ve acrecentada con el imaginario de conflictividad social que existe en torno a los centros - especialmente públicos- de ciertas zonas de la ciudad. La opción de estas familias ha sido buscar centros privados que "garanticen" aquella seguridad que demandan.

La segunda razón por la que se considera la educación privada como la opción «más válida» es debido a la oferta de una educación de carácter religioso, característica que predomina entre los centros privados de la ciudad de Granada. En el caso de aquellos padres que se definen a sí mismos como «practicantes», la selección de un centro que participe de dichas convicciones se convierte en un aspecto prioritario, al menos a nivel discursivo:

También iba buscando una educación religiosa, que tuviera cierta influencia religiosa, y me gustaban los privados. (Rosa)

Y, evidentemente, yo soy católico y creo que el catolicismo no te va a decir nada negativo para la formación de una persona. [...] Yo he recibido esa misma información, no me ha ido mal en la vida y quiero que ellos también reciban 
esa misma información y la están recibiendo. Y creo que estamos formando unas personas bastante aceptables para el futuro. (Julián)

La elección de un centro religioso está muchas veces vinculada a la experiencia personal de estos padres. Los «antecedentes» de los que disponen y su propia experiencia en colegios religiosos validan la opción tomada en el presente. Esto permite que algunos padres soslayen los estereotipos que, según ellos mismos, existen sobre los centros religiosos:

P: [...] a mí me gustaba también que estuviesen en colegios religiosos. [...] Pues porque yo he estado en religiosos. Me ha ido muy bien. [...] Por mucho que digamos: «Uh, tanta misa, tanta misa, y todos los días...». Pero luego, en el fondo, eso está ahí. (Puri)

Yo, el colegio, por ejemplo..., una formación religiosa del colegio y no somos muy religiosos, ni mi marido ni yo [...] pero como yo sabía que yo no le iba a dar esa formación que ellos van a necesitar, quería que la complementaran un poco no, porque yo los puedo llevar un día a misa pero no voy a saber darle una catequesis, por decirlo de alguna manera, porque a lo mejor yo tengo esa formación, esa base. [...] y entonces digo, pues bueno, por darle, formarlos un poco más de lo que nosotros pudiéramos dar. (Mercedes)

Mercedes abre un nuevo frente a la hora de interpretar la opción unilateral por centros de corte religioso. Como sus palabras denotan, siempre se busca un añadido, algo que debe darse, además del carácter religioso del mismo. A medida que nos adentramos en la conversación con la propia Mercedes, este atributo sale a relucir de forma mucho más clara:

Lo primero que queríamos era un colegio religioso, que tuviera, pues..., dentro de lo que nosotros conocíamos, dentro de las... como siempre preguntas te informas..., pues que tuviera un buen sistema educativo dentro de lo que nosotros creemos, considerábamos, que tuviera buena... buen nivel ¿̨no? (Mercedes)

Este aspecto es especialmente importante, ya que, como en el caso de algunos padres entrevistados, si no se comparte formalmente una creencia basada en principios y vivencias religiosas, sí se admite y se acepta que el marco moral propuesto por este tipo de centros es adecuado. Si bien estos padres no se reconocen en el perfil de persona religiosa y practicante, ellos aspiran a que sus hijos sean formados con un determinado esquema valorativo y, quizás más importante aún, reconocen que se encuentran imposibilitados para transmitirlo, ya que no participan de dicha experiencia religiosa.

J: Nosotros no somos una familia practicante. [...] yo por lo menos con todas mis contradicciones, no me veía yo capacitado para darle esa formación a mis hijos. Pero, por historias, o por las contradicciones que teníamos, sí queríamos que nuestros hijos entraran por ahí y luego, ya, decidieran [...] 
R: Sí, pero yo más que el hecho en sí de lo que es la parte religiosa... J: Una serie de valores... orden... (Rosa y Jorge)

Tal como mencionamos, las acciones desarrolladas en el momento de la elección de centro están destinadas a conseguir un entorno escolar que asegure que se logren los objetivos trazados para la educación de sus hijos. Para disminuir la ansiedad que esta situación les provoca, muchos padres buscan minimizar las oportunidades de contacto con determinados grupos sociales pagando por entrar a centros privados, la mayor parte de ellos religiosos. En estos centros, además de mayor selección social, gracias a la barrera de ingreso que significa el costo económico, encuentran una formación en valores que ellos consideran cercana a lo vivido en sus propios hogares. Favorecer la interacción con compañeros «similares» a ellos y fortalecer el andamiaje moral de sus hijos son, por tanto, parte de una misma empresa a la que muchos de los padres entrevistados dedican ingentes esfuerzos y recursos. En ese sentido, cabe preguntarse si el incremento de la percepción de riesgo entre los padres de clase media, producido socialmente pero vivido individualmente (Bauman, 2002), se puede estar traduciendo en el fortalecimiento de las líneas de división social (Ball, 2003c) y en la selección cuidadosa de los centros escolares, con el objeto de fortalecer la propia identidad de clase. Esto introduce la necesidad de valorar qué tipo de racionalidad es la que desarrolla este grupo de padres y ver en qué medida ésta constituye el despliegue de cierto habitus de clase que luego se expresa en las elecciones que cada una de las familias toma individualmente.

\section{La escuela pública: entre la «solidaridad» y la «distinción»}

Los padres de clase media que optan por la educación pública suelen defender esta opción, en un primer momento, desde un prisma ideológico. En ese sentido, nos encontramos con un tipo de racionalidad diferente a la de los padres que escogen centros privados. Referencias a los valores democráticos, el pluralismo, el bien común, la apertura y la tolerancia, entre otros, son la bandera de este grupo de padres, algunos de los cuales se definen a sí mismos como "progresistas", como ocurre en el caso de Paula:

Y, entonces, pues, cuando tuvimos hijos, pues, más o menos, los dos teníamos claro que queríamos la enseñanza pública. ¿¿Por qué? Bueno, primero porque más o menos tenemos una ideología progresista y queremos defender la enseñanza pública, y creo que la mejor forma de defenderla es usándola y no mandando a tus hijos a la privada. (Paula)

Yo soy un claro defensor de la escuela pública [...], no sólo porque objetivamente creo que es lo más adecuado, la escuela de todos, la escuela multicultural, la escuela más democrática, más abierta, más tolerante sabiendo que allí los elementos singulares como profesorado y tal, puede haberlos realmente de todo, pero en su conjunto, como institución, a mi me parece que es lo que se aproxima más a lo que pienso de lo que debían ser estos grandes servicios como 
la sanidad o la educación, siempre he tenido claro, por tanto, ser coherente entre lo que pensaba y lo que hacía, y de hecho mi hijo empezó en primaria, bueno infantil primero y luego primaria, en un centro público de Maracena. Ahí terminó su primaria y pasó al centro de secundaria que hay en el pueblo. (Pedro)

La argumentación desarrollada por algunos de los padres entrevistados y que envían a sus hijos a centros públicos concuerda con lo que James et al. (2006) denominan el comunitarismo "duro». En estos casos, la elección escolar está centrada en la comunidad, el localismo, y expresan un fuerte sentido de solidaridad. Para ellos, la decisión de enviar a los hijos a la escuela pública es una extensión de un compromiso social y político personal que se expresa también en otras facetas de su vida. Consideran, asimismo, que la experiencia de sus hijos en la escuela pública es beneficiosa y contribuye a mejorar su desarrollo integral como personas. Estos padres manifiestan, como también apuntan Jordan y sus colegas (1994), un abierto rechazo a la selección del alumnado en función de su procedencia social, tal como se produce en los centros educativos concertados y privados. Estos padres cuestionan dichas prácticas por su carácter elitista, lo cual no concuerda con sus ideales y sus planteamientos ideológicos y políticos. Aunque perciben "problemas" $\mathrm{y}$ "situaciones peligrosas" en la educación pública, e incluso que se pueden llegar a experimentar en primera persona, ellos no encuentran otra alternativa válida para escolarizar a sus hijos.

A: Bueno, ella cuenta anécdotas del instituto de aquí, dices yo... Conozco a todos los delincuentes... Oye, y me llevo bien y todas las cosas, pero..., por allí en las clases, bueno, venderte chinas y cosas de esas, pero..., fácil ¿̨no? Llegar los críos con las motos..., bueno, bueno... Dices, allí has visto... Se ven cosas que tú no te puedes imaginar, seguramente será menos, que la ilusión de los críos la magnifique y tal, pero que..., que si... Citas para pelearse..., al salir del... Bueno, ha intervenido la policía... Hubo un conflicto, en ese sentido...

E: ¿Pero siempre la habéis mantenido ahí?

A: Pero la he mantenido ahí, sí, sí..., porque... la alternativa es una educación elitista fuera de... sitio. Yo no creo... No me parece adecuado. (Álvaro)

Esta percepción respecto a las experiencias de los hijos en la escuela pública es uno de los aspectos más valorados por los padres de clase media que eligen este tipo de educación para sus hijos. Ellos buscan que sus hijos se encuentren en un ambiente que sea reflejo de la «vida real», de la vida «fuera del colegio». Esto, sostienen, diferencia a sus hijos de los chicos de los centros privados, quienes vivirían, como señala Pedro, en una «urna de cristal», sin mayor contacto con el mundo.

Entonces era un poco..., o bien delegar la educación de mis crías en un colegio, y un poco que fuera lo que Dios quisiera, o bien tomar más parte en la educación de mis crías a través de un colegio público... No sé si... ¡Claro!, un 
colegio público, que era más real con la vida que..., que nosotros llevábamos ¿no?, puesto que eran, todos sus vecinillos que iban al mismo colegio. Había una continuidad entre las amistades en la calle y las amistades en el colegio, y un saber..., lo que en la vida te viene, no es sacarlo de... Luego vienen a tu casa, aquí no se relaciona con nadie, una educación muy experimental... (Álvaro)

Sin embargo, este aspecto también puede ser interpretado desde una perspectiva diferente, iluminando la relación conflictiva entre integración y diferenciación de los estudiantes de origen social distinto en el interior de la escuela pública, en particular en el contexto de una creciente huida de las familias de clase media de este tipo de centros (Fernández Enguita, 2008). Es el caso del tipo de padres que corresponden, según James et al. (2006), a la categoría de comunitaristas «suaves». Ellos asumen un riesgo calculado al escoger la escuela pública, lo cual disminuye la intensidad de la orientación ética que los mueve. Sus hijos se ven beneficiados por la interacción con una mayor diversidad social, pero, al mismo tiempo, como padres, buscan mitigar los posibles «daños» por la elección tomada y, si fuese necesario, no tienen dificultad para abandonar la opción de la educación pública. Por esto, suelen fortalecer el rol compensador de la familia, aspecto que se encuentra favorecido por su mayor capital cultural. También se aseguran, como veremos más adelante, que la escuela pública escogida posea el nivel académico o el prestigio social que ellos consideran apropiados. Como señala Ball al analizar fragmentos de entrevistas similares en su estudio llevado a cabo en Londres: "podemos ver la importancia otorgada a la construcción de identidad y distinción de uno mismo frente a otros. [...] El sentido de mezcla social en las escuelas, que es, a la inversa, una representación de exclusividad o cierre, está situado dentro de una conciencia experimental de la demografía local» (2003a: 63). Visto así, dicha elección por la heterogeneidad no sería sólo una apuesta por la igualdad y la justicia social, sino, de cierta forma, también se puede ver como una herramienta más utilizada por dichas familias para afianzar la creación de una identidad de clase «diferenciada» por parte de sus hijos. Esta ambigüedad también se expresa en el discurso de este conjunto de padres de clase media, donde "se habla más de la bondad de "conocer" personas de otros niveles socioeconómicos más que de "hacerse" amigos de ellos e integrarlos en sus redes» (Power et al., 2003: 61).

En esta misma línea, los autores advierten ante la posibilidad de «romantizar las escuelas comprensivas como proveedoras de entornos donde todos los estudiantes puedan entrar y donde las redes sociales traspasaran las fronteras culturales y de clase» (ibídem: 59). Tal como observamos en los siguientes fragmentos, los padres de clase media tienen conciencia de la especificidad de sus hijos en el interior de los centros públicos. Esta especificidad se expresa, al menos, en dos aspectos: por un lado, en una clara conciencia que asistir a un centro público constituye una opción ética tomada por estas familias de clase media y que es disonante respecto a la conducta de sus pares sociales; por otro, y dado que esto es una opción, siempre se puede desandar el camino cuando 
surjan problemas, el nivel académico se evalúe como inapropiado o se considere que está en riesgo el futuro del hijo. Por lo mismo, aquellos padres que escogieron dentro de la red pública buscaron, dentro de la oferta existente en esa red, centros que cumplieran algunos requisitos mínimos. Elsa, por ejemplo, opta por un centro público, no por falta de recursos económicos, como ella misma afirma, sino por "criterio». A su vez, ella es maestra en un centro de titularidad pública, por lo que conocía el funcionamiento del sistema y disponía de los contactos suficientes para asegurarse que sus hijos pudiesen entrar en un centro de primaria con «muy buenos niveles» y en la misma zona de un instituto de gran prestigio en la ciudad, en el cual, por cierto, cursaron la educación secundaria y el bachillerato.

A lo mejor no llegan a los niveles de los [concertados religiosos], porque allí van otro tipo de alumnos, como te digo, padres muy selectivos que son capaces de pagar lo que haga falta. Yo no era por el dinero, porque el dinero, los medios, los tenía, era por criterio, como te digo. Y, bueno, decidí por eso, por ese criterio de esa compañera que me informó que allí había unos niveles muy buenos. (Elsa)

Por su parte, Álvaro, al mismo tiempo que valora la heterogeneidad social de la clase de sus hijas, reconoce que era consciente de la «buena fama» del centro al que ellas accedieron y que les correspondía "por zona». Este último llega incluso a reconocer que, en caso de problemas, se «hubiera tenido que plantear qué hacer»:

Era el que les correspondía, y además, pues la verdad, tenía buenas referencias además. Ésa es de las veces que menos conflicto me creó..., porque, dentro de la enseñanza pública, hay sitios y sitios ¿no? ¡Hombre!, pues teóricamente aquí en Maracena tenemos una semipública, son las monjas.... Y las monjas tenían mejor fama que el colegio público, pues no quería monjas, vamos..., monjas de niñas solas..., que no, no queríamos... Han ido las tres... Hombre, a lo mejor si las cosas hubieran ido mal, me hubiera tenido que plantear qué hacía..., probablemente... Es que no me fueron mal..., no fueron mal las crías. [...] Y, dentro de eso, el [público] teóricamente, pues de lo que hay..., de la gama, pues, por lo menos tiene fama... (Álvaro)

Este tipo de discurso que destaca la heterogeneidad de la educación pública suele aparecer solo en el caso de quienes han elegido esta opción. Manuel señala una dinámica que se produce en el seno de la educación pública y que estaría directamente relacionada con dicha selección del alumnado. De hecho, él la denomina como «selección natural», refiriéndose a que, con el paso de los años y gracias a las «barreras» presentes a lo largo del proceso educativo, el propio sistema iría dejando atrás a un número determinado de alumnos.

[...] si tú vas al instituto, pues hay tres primeros de ESO, tres segundos, y conforme van subiendo los cursos, quedan menos... Hay un primero de bachi- 
llerato de ciencias, o sea, que ya la selección... Los mismos niños se..., abandonan los estudios. [...] Pero que eso es la selección natural como yo digo [...] allí en el instituto pues son exámenes, y..., el que aprueba, aprueba y pasa, y el que no aprueba, pues no pasa... Es como..., una selección. (Manuel)

En suma, las motivaciones que mueven a las familias de clase media a elegir un centro público se presentan de forma más compleja que lo que en un primer momento pudiera concluirse. Se puede afirmar que el perfil de padres que asisten a la educación privada es más heterogéneo que el de aquellos padres de clase media que escogen la educación pública. En el caso de estos últimos, suelen corresponder a familias cuyo principal capital es el cultural y que, a su vez, han experimentado de forma satisfactoria, al menos uno de los miembros de la familia, la educación en centros públicos durante su etapa como estudiantes.

\section{El proyecto educativo: un punto de confluencia entre escuela y familia}

Un segundo aspecto que destacamos en nuestro estudio es la importancia concedida por las familias de clase media a la existencia de un proyecto educativo claramente definido en ambas instituciones: la familiar y la escolar. Existe una particularidad a este respecto, ya que tan sólo los padres cuya elección se decantó por centros privados aluden a este aspecto. Para estos padres, la pérdida de valores en la escuela pública explica y legitima su elección por la educación privada:

También me interesaba un poco el funcionamiento de los equipos docentes en el aspecto curricular. [...] De organización, de coherencia de los equipos, de continuidad, de no excesivo individualismo y tirar cada uno por su lado, sino un proyecto, que estaba, que en el momento en que, entiendo, que hay un equipo docente que funciona es que, al menos debajo, hay un proyecto mínimo educativo, de trabajo y en muchos ámbitos. Desde la eficacia, a lo mejor, en las estrategias de enseñanza hasta en los valores que se puedan ir incorporando en el trabajo. (Valentín)

Como se observa, se busca que exista sintonía entre el proyecto familiar y el centro educativo. Esto implica la existencia de una importante conciencia e intencionalidad respecto a lo que se pretende alcanzar con la educación por parte de la familia y el papel que ésta desempeña al respecto. De esta forma, puede afirmarse que en aquellos momentos importantes en los que la identidad familiar está en juego, y la elección del centro escolar es uno de ellos, las familias, especialmente los padres, toman conciencia de su propio habitus, y cogen las riendas del proceso de creación de clase social, con lo cual favorecen procesos de reproducción social. En la misma línea apuntada por Taylor (2001), los padres primero eligen el tipo de "producto" particular que quieren y después se deciden por la escuela concreta que les ofrece ese producto: 
Aparte que no en cualquier colegio. También elegimos el colegio privado que mejor nos parecía a nuestra forma de pensar. Bueno, pues, estamos contentos. (Marta)

Porque si yo les doy una educación, en el centro le dan otra diferente y luego, los amigos, recibe otra cosa distinta, pues, el chaval se está haciendo un lío. [...] Como te he dicho antes, nosotros hemos puesto la base. Y nosotros hemos querido que esa base se mantenga en el centro que hemos elegido para nuestros hijos. Nosotros complementamos la educación que reciben nuestros hijos allí con la que nosotros les damos en la casa y a la inversa. (Julián)

Aquí encontramos dos aspectos que deben ser considerados. Por un lado, se demuestra la importancia concedida por estas familias a la educación, dado el esfuerzo que dedican a descodificar en profundidad el funcionamiento de los distintos centros. Y, por otro, estrechamente vinculado con el anterior, se observa una importante acumulación de capital cultural válido para analizar estos elementos. El análisis y la importancia concedida a los proyectos educativos de los centros denota una especial dedicación en términos de tiempo y esfuerzo, pero, a su vez, supone que las familias cuentan con las herramientas necesarias para poder comprenderlos y descodificarlos, no sólo en términos académicos, sino también, de forma más amplia, en relación con la «formación integral de la persona»:

C: Nosotros analizamos muchísimo el proyecto educativo, estuvimos en muchísimas reuniones con todo el equipo, el equipo de dirección...

E: ¿Qué os interesaba de eso?

C: Pues, efectivamente, lo que es el proyecto educativo. O sea, no si vamos a dar hasta las raíces cuadradas o solamente cuántas horas de matemáticas... Lo que nos importaba realmente era que cuidaran la formación integral de la persona. (Consuelo)

Fruto de este tipo de análisis, estos padres descubren que no todos los centros presentan proyectos educativos apropiados para ellos. En ese sentido, es necesario señalar el filtro impuesto sobre los distintos centros por la existencia de un plan educativo familiar, un «ideal de persona» y la conciencia de los mecanismos por los que se llega a realizar este último, por medio de una educación de características muy concretas. La tarea, entonces, será encontrar un centro que se equipare al «proyecto educativo» existente en la familia:

Y ahí pienso que la pública deja mucho que desear [...] Porque pienso que no hay un proyecto educativo, como tal. Está, desde mi punto de vista, bastante politizado. No son los objetivos, aunque te encuentras de vez en cuando al típico maestro, pero cuando conoces un poco, porque lo conoces de fuera y has tenido la oportunidad... Y no ves al mismo profesorado motivado. Para mi es fundamental que si tú no estás motivado y estás metido en un proyecto, tú no puedes transmitir eso. [...] Por ejemplo, yo en el [privado] lo que he encontrado es un proyecto educativo, y los profesores están inmiscuidos en 
ese proyecto, con lo cual trasmiten algo. Igual que, por ejemplo, pues, me costó muchísimo estrés los años de Ignacio en..., habiendo un proyecto educativo, pero en cambio no estaban los valores que yo consideraba que debían estar en el niño. [...] para mí el colegio es, como te he dicho antes en la guardería, es una continuidad de la casa, o sea, no es que el niño vaya a aprender allí a sumar y restar y se vuelve. El niño allí va a aprender valores éticos, valores morales..., o sea, va a aprender algo más. Entonces, pues, siempre esperas de ese colegio algo más, y yo, pues, en el colegio público, en la primaria, no lo veo. (Consuelo)

Se puede observar cómo existe un claro sentido de continuidad entre la escuela y la familia con respecto a los principios educativos. Lo que se valora y se pide en un sitio es similar en el otro, y así los jóvenes no encuentran disonancias que distorsionan su esperado desarrollo. En este sentido, podríamos definir el hogar como un «segundo lugar de escolarización» (Ball, 2003b).

Es aquí donde el carácter público o privado de los centros se introduce como elemento explicativo en nuestro modelo. Como decíamos, son exclusivamente los padres que han optado por centros privados aquéllos que hacen referencia a la existencia de proyectos educativos acordes entre el de la familia y el del propio centro. De forma generalizada, estos padres sostienen que existe un fuerte individualismo y una elevada politización en el profesorado del sector público, principalmente en aquéllos de educación secundaria y bachillerato. Esto impediría la creación de proyectos compartidos en los centros, y que éstos fueran visibles para las propias familias, al contrario del fuerte sentido de trabajo en equipo que éstas perciben en la escuela privada. Consecuencia directa de esto último, según estas familias, es el «carácter integrado» y homogéneo de dichos proyectos.

[...] la libertad con la que venimos funcionando como empleados públicos y la menos libertad profesional que tienes como empleado en un centro de la concertada. Pero eso es un elemento, entiendo yo, un factor que está jugando quizás a que se posibilite, ¿̨no?, un poder trabajar más en grupo y menos individualmente. [...] En la concertada que se pueda trabajar más en equipo. (Valentín)

Otro de los aspectos especialmente valorados es la posibilidad de continuidad dentro del centro durante todas las etapas propuestas por el sistema, desde la primaria hasta el bachillerato. El que los hijos no tengan que cambiar periódicamente de centro, se mantengan en un entorno estable que garantice la comunicación entre los profesores de los distintos cursos y la posibilidad de evitar posibles distracciones en dichos pasos, se considera un rasgo destacable de los centros educativos concertados y privados, los cuales, mayoritariamente, ofrecen todas las etapas educativas, a diferencia de los centros públicos:

Lo cierto es que en la concertada ves una mejor organización escolar, una mejor organización del currículum. Juega también, quizás pueda jugar también, el 
que, en este caso, en el mismo centro, puede ser un elemento, puede ser un factor, no lo sé, de continuidad, desde infantil hasta bachillerato, debe serlo, es más fácil el traslado de información de una etapa a otra, el conocimiento del alumnado, más como su casa, desde chicos..., a ir cambiando de un centro de infantil, primaria, otro de secundaria, ¿no? Veo un mayor escalonamiento en el área, en las áreas de aprendizaje. (Valentín)

Por último, al igual que ocurriera con la elección entre pública y privada, el proyecto educativo del centro es utilizado como una herramienta de selección del tipo de alumnado que asiste al centro. Este aspecto es valorado por los padres entrevistados, pues garantiza que no todas las familias tengan cabida en un determinado centro:

Simplemente, para mi punto de vista, el tema de selección es importante a la hora de que si tú quieres llevar a cabo realmente un proyecto educativo. Es que parece como una fantasmada y al final es un negocio: yo pago y el niño recibe clases, recibe más clases de la cuenta porque pago, y, además, encima de todo, le puedo exigir al profesor. Hasta ahí ésa es la imagen, desde mi punto de vista, fría de lo que es un colegio privado. Fría, cierta, cierta y fría. No es la mía. La mía es que si los niños están ahí es porque yo he decidido pagar su enseñanza, y yo le exijo al colegio que haga la continuidad que tengo yo. (Consuelo)

La importancia concedida a la existencia de un proyecto educativo, "público y publicitado", puede entenderse como el resultado de la puesta en práctica de una nueva estrategia de cierre social excluyente por parte de las familias de clase media. La diferencia, en este caso, es que son las familias las que estarían forzando para que dicha selección y exclusión la realizaran los propios centros, en base a criterios «oficiales», lo cual descargaría de «responsabilidades» a estos últimos con respecto a los efectos sociales de dicha selección.

\section{El ambiente general de un centro: la búsqueda del entorno propicio}

Una vez examinado el proyecto educativo, la siguiente característica que debe cumplir el centro, ya sea de un centro educativo público o privado, es que disfrute de un «buen ambiente». En una investigación en la periferia de París, Van Zanten muestra cómo las familias de clase media se presentan «fuertemente protectoras respecto a la experiencia escolar de sus hijos y respecto a la elección de escuelas que tienen reputación de disfrutar de un buen "clima" " (2003: 113). Este «buen ambiente» es experimentado de forma distinta en función del tipo de escuela. Aquéllos en escuelas públicas valoran la dimensión social del centro, pero expresan ansiedad respecto a que sus hijos puedan encontrarse con un «mal grupo» o los problemas «típicos» relacionados con este tipo de centros. Como vemos en el siguiente caso, la valoración sobre la calidad de los centros públicos tiene como un componente importante el ambiente escolar y, por lo mismo, en la medida que la vivencia cotidiana no corrobore la 
imagen negativa existente sobre este tipo de centros, la experiencia será bien evaluada por los padres. En este proceso, la realidad experimentada en forma directa es confrontada con las representaciones sociales, generalmente negativas, que existen sobre la educación pública, muchas de las cuales son construidas por los medios de comunicación (Mac Millan, 2002).

P: Ese instituto está bien, ese instituto tiene gente seria. Son gente trabajadora y es un instituto que hay buen ambiente, que para mí es también muy importante.

O: ¿A qué te refieres con que es un buen instituto?

P: Que no hay problemas de disciplina o problemas de esos que salen en la tele, de violencia escolar, violencia en las aulas... Parece que no hay demasiada droga, ya no lo sé, de eso, al menos, yo no me he enterado [risas]. Pero parece que no, parece que no, en este tema. (Paula)

Otro de los riesgos que se presentan dentro de la enseñanza pública, como también observan Power y su equipo, es que sus hijos no fueran lo suficientemente motivados en estos contextos, "o sean discriminados y estigmatizados por ser "demasiado inteligentes"” (Power et al., 2003: 52). En nuestro estudio, encontramos esta misma situación cuando Manuel narra la experiencia negativa de su hijo precisamente por su buen desarrollo a nivel académico:

M: [...] te voy a contar una anécdota. De hecho, a mi hijo, el menor, en primero de ESO, que cayó en un curso muy, muy malo..., muy malo, le amenazaron de que si sacaba más de un 7 le pegaban...

E: ¿Los compañeros?

M: Sí, sí, los compañeros... Unos compañeros, no todos... Entonces el niño me lo dijo a mí.... y yo tuve que ir a buscar al niño a la puerta del instituto, porque había una gentuza, porque era una gentuza... Amenazar a un niño porque saque buenas notas..., y ya estuve hablando con ellos. (Manuel)

De forma opuesta, esta sensación de riesgo es menor en aquéllos que han elegido escuelas privadas selectivas. Podría decirse que existe una percepción de que la inversión económica que están realizando protege, de alguna forma, a sus hijos de esos problemas y garantiza un ambiente que favorece y reconoce positivamente el éxito académico (Power et al., 2003). En los colegios privados, se ofrece un mayor "control» sobre el ambiente, al menos de forma indirecta, y se vigila, a su vez, a la población de los mismos, de forma que será el propio centro el que «limpiará» el ambiente, con lo cual restaurará la «seguridad», como vemos en los siguientes fragmentos:

E: No, jamás de público. [...] Primero ni hablarlo entre nosotros. No me hubiera gustado. ¿̇Por qué? No por la enseñanza en sí, sino por el ambiente. O: ¿Qué diferencias ves tú ahí?

E: Pues, mira, yo he pasado por institutos... No lo sé. No hay control ninguno...

O: Cuando dices que has pasado, ¿has pasado por fuera? 
E: Por fuera, he visto los recreos de los niños y, control, ninguno vi. Ahora ya será más normal, pero..., el porrito fumándolo... Que lo hacen aquí porque aquí salen fuera y lo hacen, pero no era dentro del mismo... Y, no lo sé, no me agradó el ambiente que vi de compañeros. (Enriqueta)

Porque... [en los centros privados] hay un ambiente... cordial, porque los profesores..., se puede hablar con ellos..., les puedes plantear... vemos que están preocupados porque..., porque el colegio... vaya bien... vaya a mejor... [...] No es morralla, ni es morralla..., por decirlo de alguna mala manera mal expresado..., ni tampoco a un garbanzo negro lo permiten mantenerse mucho tiempo... En cuanto detectan un garbanzo negro, limpian la era..., como digo yo. Eso te da, pues..., esa seguridad... En fin, no sé que decirte más. (Paula)

De acuerdo con estos padres, para saber el tipo de alumnado y el ambiente que "respira» un centro, es suficiente con "pasar por la puerta» de los mismos durante la entrada o la salida de los niños, en particular, para observar el ambiente que predomina entre los padres y las madres que se acercan a llevarlos y recogerlos. Mercedes expresa de forma muy gráfica este aspecto. Para ella, es importante garantizar la homogeneidad de las familias, ya que el control del alumnado es difícil de lograr:

Bueno, pensamos que puede ser un buen ambiente, de familias que creemos que más o menos están como nosotros. Si yo no pido otra cosa [...] Yo por ejemplo tengo aquí un colegio muy cerca, muy cerca, que es el [público]. [...] Un poco lo que te he dicho, el ambiente. Yo pasaba por la puerta cuando mis hijos eran pequeños y el ambiente de las familias que se veían en la puerta pues a lo mejor no me gustaba... No es por discriminar, pero es que no me gusta, se me está poniendo la palabra y no me gusta usarla, eh... A lo mejor, pues..., muchos gritos, muy mal hablados [...] Así de principio ves a las madres un poco como llaman a los niños, y ya te echa un poco para atrás. (Mercedes)

Distintos padres entrevistados subrayan el hecho que en los últimos años la educación concertada tampoco puede garantizar este «buen ambiente», lo cual parece estar favoreciendo el crecimiento en la matrícula que ha experimentado la escuela privada ${ }^{2}$. Como hemos visto, los padres manifiestan una especial preocupación por el grado de control de distintos elementos relativos al orden expresivo de los centros. El ambiente del que éstos gozan, el control establecido por el mismo y el comportamiento de sus integrantes, en sus distintas dimensiones, son aspectos clave a la hora de formarse un juicio sobre los mismos. Pero, a su vez, los padres de clase media también dan importancia a

2. Entre los años 2001 y 2008 , la matrícula de la red privada ha crecido sostenidamente en los diferentes niveles educativos, al contrario de lo ocurrido en las redes pública y concertada de Andalucía. En el caso de la educación secundaria, la matrícula en escuelas privadas ha crecido un $16 \%$, mientras que decrece un $3 \%$ y un $10 \%$ en las redes pública y concertada, respectivamente, en un contexto donde desciende el número de estudiantes en general. Véase Estadisticas de la Educación de Andalucía (web). 
aspectos relacionados con el ambiente, que se podrían situar dentro de aquellos pertenecientes al orden instrumental. El aspecto físico del edificio y el cuidado que se tiene del mismo son elementos evaluados por los padres, en tanto reflejarían el grado de preocupación existente en los distintos centros por el contexto educativo en que sus hijos se desarrollarán. Para muchos padres, la imagen física del centro también les habla del tipo de ambiente que hay en determinadas instituciones escolares. Una particularidad de estos juicios es que proceden a partir de generalizaciones. Así, por ejemplo, lo público se relaciona con dejadez, desorden y poco interés, lo cual, para estas familias, deja su huella en la imagen externa del centro, de forma que puede distinguirse «a simple vista» la titularidad de un centro por su aspecto físico, por la existencia o no de ese «decoro»:

Tú llevas a unos padres, sin saber dónde van, tú los dejas en un centro y dices: «Mira, este centro tiene la misma antigüedad que éste. Tú velo y decide». Yo te garantizo que el cien por cien elige el privado. Lo público, por la consideración de lo público, te da una sensación de abandono y de desastre que es la leche. $\mathrm{Y}$ vas a un centro privado, donde está tutelado, donde..., claro, y dices: «Si es que este centro es más nuevo que éste», está todo perfecto, todo... Y yo quiero que mi hijo se desenvuelva en ese tipo de ambiente, más que en el otro. El..., ya, el aspecto exterior, las formas externas, ya de entrada, te seducen, ¿entiendes lo que te digo? Mira, yo hago reconocimientos escolares, por mi trabajo, y $[\ldots .$.$] en mi zona hay once centros escolares. Y lo comentamos los$ compañeros. La manera con que te llevan un curso a que tú lo vacunes. Dices: «Esto se nota que es público, se nota que es privado...». Eso es un decoro, es un..., o sea, un hacer las cosas en condiciones. Y ese tipo de cosas se le transmite a la gente. En los públicos, aquello es la repolla: un escándalo en la puerta, un desorden, un poco interés... El profesor los deja allí y se va. Mientras que van colegios de los otros y cada niño entra con su cartilla, no se oye una mosca, es una cosa..., una cosa que dices: «Esto es distinto». ¿Por qué pasa eso? Pues no lo sé, quizás sea la cosa que tiene lo público. (Jorge)

Este tipo de juicios dicotómicos acerca del cuidado y la calidad de la infraestructura suele reafirmar la voluntad de algunos padres de no enviar a sus hijos a centros públicos. Ante esta situación, la solución para alguna de estas familias es realizar una nueva inversión En este sentido, el capital económico puede asegurar el acceso a un centro que cumpla adecuadamente en esta dimensión instrumental, cerciorándose que existan determinados servicios que ellos consideran indispensables.

Hace unos años, no tenían pabellón en el colegio. Tuvieron que establecer una cuota especial para hacer un pabellón. Y se hizo un pabellón deportivo. En un colegio público, no hay que hacer esas cosas. Socialmente, el Estado, cuando le viene bien, te lo construye y, si no, pues, tu hijo no tiene un pabellón. Yo quiero que mis hijos tengan un pabellón [...] Yo no quiero que mi hijo entre a los servicios y se encuentre los pegotes de suciedad en los servicios. Yo quiero que, cuando mi hijo entre en un servicio, entre en un servicio limpio, un 
servicio que esté en condiciones. Que me cuesta el dinero, pues, vale, pero yo prefiero pagar para eso. [...] Justamente enfrente de donde yo vivo hay un colegio público, que han llevado vecinos de allí a sus niños, y nada más empezar el primer año estuvieron una semana sin poder entrar en clase porque se habían atascado los servicios y salía la suciedad por las escaleras abajo. Entonces, yo me alegré muchísimo de que mi hijo no estuviera en un tipo de centro así. (Julián)

Como se observa, lo público presenta una imagen devaluada, lo que se debería a falta de organización y problemas de gestión. En suma, sería el reflejo de un servicio educativo de menor calidad.

\section{A modo de síntesis}

Siguiendo la división propuesta por Bernstein (1988) para estudiar las relaciones entre alumno, familia y escuela entre orden expresivo y orden instrumental, hemos analizado el proceso de valoración que realizan los padres respecto del primero en el momento de escoger centro para sus hijos. Para ellos, «la mejor escuela» no es tan sólo la que obtiene los mejores resultados en las distintas etapas. Aspectos como el prestigio social, generalmente medido en función de la población que asiste a un determinado centro, su carácter y su proyecto educativo, el que sea de titularidad pública o privada o el ambiente general del mismo, son dimensiones relevantes en la definición que los propios padres construyen de la «excelencia» educativa. El análisis de las entrevistas a los padres de clase media muestra que el modo en que ellos eligen centro no suele responder a los patrones ideales prescritos por los defensores de las políticas de cuasimercado.

También hemos mostrado que el comportamiento de estos padres no es homogéneo, aunque sí existen ciertos rasgos que tienden a predominar. La mayor parte de los entrevistados valora la existencia de selección social en los centros, pues esto permite que sus hijos estudien con alumnos de similares características socioculturales, con los que comparten aspiraciones y valores. Para conseguir esto, ellos despliegan un conjunto de estrategias y hacen uso de los distintos capitales de que disponen. Un modo es asistir a los centros públicos que cuentan con prestigio social y, por esta misma razón, suelen ser reconocidos como de buena calidad. En caso de que no sea así, la inscripción en escuelas privadas o concertadas es una opción habitual, ya que suponen que en éstas existirá un mayor control sobre el tipo de alumnado.

Debido a lo anterior, y más allá del grado de autoconciencia de cada uno de los actores sobre este punto, el efecto es que el proceso de elección de institución académica se sitúa en el centro de aquellas dinámicas destinadas a posicionar a los hijos en una situación privilegiada y ventajosa frente a otros. La racionalidad que subyace a tales prácticas se compone tanto de elementos utilitaristas como de otros dominados por racionalidades que no pueden ser subsumidas bajo la lógica del cálculo racional y que suelen estar teñidos de un fuerte 
componente cultural (Hatcher, 1998). Por ejemplo, para algunos de los padres entrevistados, el carácter del centro no es tan importante o, al menos, hay otras prioridades que lo son más, sobre todo, aquéllas relacionadas con la propia vida y la unidad familiar. Entre quienes realizan una opción intencionada por la escuela pública, algunos lo hacen como parte de un compromiso social más amplio, mientras que para otros es una estrategia de riesgo calculado. En ambos casos, sin embargo, existe una clara conciencia del "papel compensador» de la familia. Poder disfrutar de más tiempo con la familia, ir andando al colegio, comer juntos, vivir cerca de compañeros y amigos (siempre que respondan al perfil esperado de los mismos) son aspectos muy importantes para estos padres. Esto permite a los centros educativos un cierto margen a la hora de satisfacer las exigencias familiares, ya que este tipo de padres estarían dispuestos y, más importante aún, disponen de los recursos necesarios para compensar "pequeñas faltas» que se pudieran estar dando.

Aún así, es importante volver a la idea principal con la que iniciábamos este epígrafe. En la mayoría de los casos, la preocupación por la población de un centro, la categoría social, la selección y la cercanía a casa conforman un conjunto en el que unas llevan a las otras, dada la distribución social de nuestras ciudades. El cierre social mediante la educación quizás comience fuera de la propia escuela y dichos aspectos externos contribuyen al refuerzo de las dinámicas de reproducción social. Por lo tanto, para explicar estas referencias, se hace necesario un estudio más amplio, de carácter multidisciplinario, en el que se incluyan aspectos relacionados con la demografía y el desarrollo urbanístico de las ciudades, políticas de inclusión social fuera del ámbito educativo, existencia de transporte público y accesibilidad a él, etc. En este sentido, las palabras de Gorard y sus colegas son esclarecedoras al respecto, puesto que ponen énfasis en estas "dinámicas de declive» que se producen en el interior de las propias ciudades, a causa de las distintas estrategias puestas en práctica por las familias dominantes, «incrementando la distancia entre las escuelas que sirven a los ricos y aquéllas usadas por los pobres» (Gorard et al., 2002: 369).

\section{Referencias bibliográficas}

Alegre, M.Á.; Benito, R. y GonZÁlez Balletbó, I. (2008). «Procesos de segregación y polarización escolar: la incidencia de las políticas de zonificación escolar». Profesorado: Revista de Curriculum y Formación del Profesorado, 12 (2).

BaLL, S.J. (2003a). Class Strategies and the Education Market: The Middle Classes and Social Advantage. Londres: Routledge Falmer.

- (2003b). The More Things Change... Educational Research, Social Class and «Interlocking» Inequalities. Londres: Institute of Education, University of London.

- (2003c). «The Risks of Social Reproduction: the middle class and education markets». London Review of Education, 1 (3), 163-175.

Bauman, Z. (2002). Modernidad líquida. Buenos Aires, Argentina: Fondo de Cultura Económica. 
BERNAL, J.L. (2005). «Parental choice, social class and market forces: The consequences of privatization of public services in education». Journal of Education Policy, 20 (6), 779-792.

Bernstein, B. (1988). Clases, códigos y control. Vol. II. Hacia una teoría de las transmisiones educativas. Madrid: Akal.

Bourdieu, P. (1998). La distinción: Criterios y bases sociales del gusto. 2a ed. Madrid: Taurus.

Bowe, R.; Gewirtz, S. y Ball, S.J. (1994). «Captured by the discourse? Issues and concerns in Researching "Parental Choice" ". British Journal of Sociology of Education, 15 (1), 63-78.

FERnÁNDEZ Enguita, M. (2008). "Escuela pública y privada en España: La segregación rampante». Profesorado: Revista de Curriculum y Formación del Profesorado, $12(2)$.

FERnÁNDEZ Esquinas, M. (2004). «Elección de escuela: Efectos sociales y dilemas en el sistema educativo público en Andalucía». Revista de Educación, 334 (377-390).

Gewirtz, S.; Ball, S.J. y Bowe, R. (1995). Markets, Choice and Equity in Education. Buckingham: Open University Press.

Gorard, S.; TAYLOR, C. y Fitz, J. (2002). «Does school choice lead to "spirals of decline"?». Journal of Education Policy, 17 (3), 367-384.

HATCHER, R. (1998). "Class differentiation in education: rational choices?». British Journal of Sociology of Education, 19 (1), 5-24.

JAMES, D. et al. (2006). Community, capital and calculation: Secondary school choice and the middle class self. Comunicación presentada en la British Educational Research Association Annual Conference. Recuperación parcial (febrero de 2008),

Jordan, B.; Redley, M. y James, S. (1994). Putting the family first: Identities, decisions and citizenship. Londres: UCL Press.

Mac Millan, K. (2002). "Narratives of social disruption: education news in the British tabloid press». Discourse: studies in the cultural politics of education, 23 (1), 27-38.

Mancebón, M.J. y Pérez Ximénez de Embún (2007). "Conciertos educativos y selección académica y social del alumnado». Hacienda Pública Española, 180 (1), 77-108.

Olmedo, A. (2008a). «De la participación democrática a la elección de centro: Las bases del cuasimercado en la legislación educativa española». Archivos Analíticos de Politicas Educativas, 16 (21).

- (2008b). «Middle class families and school choice: Freedom versus equity in the context of a "Local Education Market"». European Education Research Journal, 7 (2).

Olmedo, A. y Santa Cruz, E. (2008). «Las familias de clase media y elección de centro: El orden instrumental como condición necesaria pero no suficiente». Profesorado: Revista de Curriculum y Formación del Profesorado, 12 (2).

Pérez-Díaz, V.; Rodríguez, J.C. y SÁnchez Ferrer, L. (2001). La familia española ante la educación de sus hijos. Barcelona: Fundación "La Caixa».

POWER, S. et al. (2003). Education and the Middle Class. Buckingham: Open University Press.

Rambla, X. (2003). «La desigualdad de clase en la elección de escuela». Revista de Educación, 330, 83-98.

Strauss, A. y CORBIN, J. (1998). Basics of Qualitative Research. Techniques and Procedures for Developing Grounded Theory. 2a ed. Thousand Oaks, CA: Sage Publications. 
TAYLOR, C. (2001). «Hierarchies and "local" markets: the geography of the "lived" market place in secondary education provision». Journal of Education Policy, 16 (3), 197-214.

VALIENTE, Ó. (2008). «¿A qué juega la concertada?: La segregación escolar del alumnado inmigrante en Cataluña (2001-06)». Profesorado: Revista de Curriculum y Formación del Profesorado, 12 (2).

VAN ZANTEN, A. (2003). «Middle-class parents and social mix in French urban schools: Reproduction and transformation of class relations in education». International Studies in Sociology of Education, 13 (2), 107-123.

VILlarRoya, A. y EsCARDíbUl, J.-O. (2008). «Políticas públicas y posibilidades efectivas de elección de centro en la enseñanza no universitaria en España». Profesorado: Revista de Curriculum y Formación del Profesorado, 12 (2). 